\title{
Desenvolvimento de um programa de mentoria por pares estudantis: um relato de experiência
}

\author{
Development of a mentoring program by student peers: an experience report
}

\author{
Ayrton Kenji Kaji' 1 | kenji.kaji@gmail.com \\ Beatriz Camargo Gazzi' (1) biacamargogazzi@gmail.com \\ Bruna Schimitd' (1) bru.schimitd@hotmail.com \\ Mariana de Jesus Silva' (1) marianajsilvao0@gmail.com \\ Maria Stella Amorim da Costa Zöllner' ${ }^{1}$ (1) stellazollner56@gmail.com
}

\begin{abstract}
RESUMO
Introdução: A transição do colégio para a universidade configura-se como um período de profundas mudanças, seja no âmbito acadêmico, social, pessoal ou familiar. Nesse processo, responsabilidades são adquiridas, fazendo com que essa transição possa ser marcada por inúmeras incertezas. Nesse sentido, o projeto "Mentorias: conectando estudantes", elaborado pela IFMSA Brazil FMT na Universidade de Taubaté, objetiva fornecer aos calouros o suporte necessário para tornar essa experiência mais gratificante.

Relato de experiência: A primeira edição do projeto foi desenvolvida ao longo de cinco meses durante o ano de 2020, organizada em quatro fases: 1. construção do material teórico para os mentores; 2 . pesquisa e seleção de calouros e veteranos interessados em participar do projeto; 3. gravação das capacitações on-line para os mentores; 4 . determinação da dupla mentor-pupilo e desenvolvimento da mentoria com posterior coleta e análise de feedback. Dessa forma, contemplou estudantes de Medicina, a partir do terceiro período, que atuaram como mentores, abordando, em reuniões remotas semanais, durante dois meses, os quatro pilares do projeto: acadêmico, pesquisa, desenvolvimento pessoal e extensão, com os seus respectivos pupilos (acadêmicos do primeiro e segundo períodos).
\end{abstract}

Discussão: O sistema de mentoria vertical por pares estudantis tem se mostrado uma estratégia promissora no preparo e na recepção dos alunos para a vida acadêmica e profissional, uma vez observado que o vínculo gerado entre calouro e veterano favorece o engajamento dos alunos recém-ingressantes com as atividades e oportunidades dentro da IES.

Conclusão: O objetivo deste relato é demonstrar, da perspectiva da equipe idealizadora, a experiência de realização do projeto, ao longo da sua primeira edição e incentivar a criação de programas e projetos em outras IES voltados para o acolhimento do calouro por "veteranos" de uma forma mais holística. Os resultados obtidos foram benéficos, tanto para mentores quanto para pupilos, para o fortalecimento do vínculo criado e do engajamento em atividades acadêmicas.

Palavras-chave: Acolhimento; Estudantes de Medicina; Mentoria.

\section{ABSTRACT}

Introduction: The transition from high school to the university constitutes a period of profound changes, whether in the academic, social, personal or family spheres. In this process, responsibilities are acquired, and it can be marked by countless uncertainties. In this sense, the project: "Mentorias conectando estudantes", developed by IFMSA Brazil FMT, at the University of Taubaté, aims to provide first-year students with the necessary support to make this experience more gratifying.

Experience report: The first edition of the project was developed over five months and organized in four phases: (1) construction of theoretical material for the mentors; (2) research and selection of interested first-year and senior students in the project; (3) recording of online training for mentors; (4) pairing of the Mentor-Mentee, development of the mentoring program with subsequent collection and analysis of feedback. To this end, medical students from the third semester onwards acted as mentors, conducting weekly remote meetings for two months, addressing the four pillars of the project: Academic, Research, Personal Development and Extension, with their respective first-year student mentee.

Discussion: The vertical mentoring system by student peers has proven to be a promising strategy in preparing and receiving students for academic and professional life, as the bond formed between the first-year student and senior helps engage the former in activities and opportunities within the Higher Education Institution (HEI).

Conclusion: The objective of the report is to demonstrate, from the perspective of the organizing team, the experience of conducting the first edition of the project in order to encourage the creation of programs and projects in other HEls aimed at new students being welcomed by seniors, in a more holistic fashion. The results achieved were beneficial, both for mentors and mentees, in strengthening the relationship created and the engagement in academic activities.

Keywords: Reception; Medical Students; Mentoring.

${ }^{1}$ Universidade de Taubaté, Taubaté, São Paulo, Brasil.

Editora: Lia Marcia Cruz da Silveira

Recebido em 02/03/21; Aceito em 24/03/21.

Avaliado pelo processo de double blind review. 


\section{INTRODUÇÃO}

De acordo com Dicionário Online de Português (Dicio) ${ }^{1}$, mentorias podem ser conceituadas como um sistema no qual alguém mais experiente ou mais velho orienta e direciona alguém mais jovem e inexperiente.

A transição do ambiente colegial para o universitário é composta por mudanças radicais em diversos aspectos, seja no âmbito acadêmico, social, pessoal ou familiar. Tal experiência pode ser tranquila para algumas pessoas, seja pela facilidade em adaptar-se a ambientes distintos ou por conhecer alguém na faculdade em que se encontra, por exemplo. Porém, para outros, a empreitada universitária que antes era um sonho pode se tornar um pesadelo ao serem arremessados no meio desse turbilhão de novas informações e sensações que é o primeiro ano da faculdade ${ }^{2,3}$.

Um exemplo desse processo de transição, que pode levar a um sentimento de despertencimento, é a atenção ofertada pela instituição de ensino ao acadêmico. A monitoração das instituições de ensino médio, geralmente, é mais individualizada e voltada ao aluno, visando oferecer o suporte para o sucesso acadêmico do jovem. Na faculdade, essa monitoração é claramente diminuída, exigindo do ingressante a responsabilidade e a proatividade de navegar pelo ambiente universitário sem esse suporte evidente da instituição 4 .

É sabido que o início da vida universitária se configura como um período de profundas adaptações. Nesse período, responsabilidades são adquiridas, hábitos são criados e, principalmente, situações constitutivas são experienciadas. No entanto, adentrar a vida acadêmica, celebremente conhecida como "os melhores anos de nossas vidas", pode ser um processo bastante turbulento, marcado por um turbilhão de sentimentos e incertezas.

Nesse sentido, foi desenvolvido, entre os estudantes de Medicina do comitê local da International Federation of Medical Students' Association of Brazil (IFMSA Brazil) e da Faculdade de Medicina de Taubaté (FMT) da Universidade de Taubaté (Unitau), o projeto "Mentorias: conectando estudantes", objetivando fornecer aos calouros o suporte necessário nos âmbitos acadêmico, emocional e pessoal, a fim de tornar essa transição mais gratificante e proveitosa ${ }^{2,3}$. Dessa maneira, o projeto foi desenvolvido e aplicado por estudantes de Medicina, de forma a abordar a interação entre pares mentor-pupilo, nos quais os pupilos referem-se aos acadêmicos do primeiro e segundo períodos, que serão contemplados, e os mentores alunos do terceiro período em diante. O projeto como um todo possuiu duração de cinco meses, sendo os três primeiros meses voltados para a criação e estruturação do projeto; e os últimos dois meses, para a mentoria em si, norteada pelos seguintes pilares: acadêmico, pesquisa, desenvolvimento pessoal e extensão.

\section{RELATO DE EXPERIÊNCIA}

A primeira edição do projeto foi desenvolvida por oito alunos membros do comitê local da IFMSA Brazil FMT que coordenaram o projeto no período de julho a dezembro de 2020 e contemplou 28 estudantes de Medicina participantes: 14 mentores voluntários (acadêmicos entre o terceiro e oitavos períodos) e 14 pupilos (acadêmicos ingressantes no primeiro e segundo períodos). A correlação entre mentor e pupilo foi realizada pela formação de duplas (um mentor ficava encarregado de um pupilo), formadas aleatoriamente por meio de um sorteio em uma live no Instagram.

Faz-se necessário salientar que todo o período de criação, desenvolvimento e realização da mentoria ocorreu durante os meses da pandemia causada pelo novo coronavírus da síndrome respiratória aguda grave 2 (severe acute respiratory syndrome coronavirus 2 - Sars-CoV-2), a mentoria foi aplicada de forma completamente virtual e remota, em que se adotaram os protocolos de distanciamento social.

Para tanto, o projeto foi organizado em quatro fases de planejamento: 1. início da construção do suporte teórico para a capacitação dos mentores; 2 . pesquisa de interesse na participação do projeto entre os calouros e veteranos, bem como a seleção dos mentores, com base em critérios previamente determinados e divulgados para os interessados; 3. finalização do material de apoio e gravação da capacitação para todos os mentores, dentro da temática a ser abordada pelos quatro pilares (acadêmico, desenvolvimento pessoal, extensão e pesquisa); 4.1. determinação das duplas de mentores e pupilos; 4.2. desenvolvimento da mentoria ao longo do período estipulado; 4.3. análise do feedback preenchido pelos mentores e pupilos ao final da primeira edição, objetivando aperfeiçoar a edição seguinte. É importante ressaltar que todos os encontros foram realizados de forma remota, alinhando-se com as normas preconizadas pelos governos federal, estaduais, municipais, bem como pela própria instituição de ensino superior (IES).

- Primeira fase: para a elaboração do material de apoio, delimitaram-se quatro pilares a serem trabalhados: 1. acadêmico, 2. desenvolvimento pessoal, 3. extensão e 4. pesquisa. A escolha desses pilares foi pautada na demanda apresentada em pesquisa realizada na própria instituição, entre os alunos veteranos, na qual foram questionados, por meio de formulário on-line, sobre quais aspectos teórico-práticos julgavam essenciais para serem desenvolvidos durante a graduação. A partir desses pilares, os coordenadores do projeto dividiramse entre os temas em que eram mais dotados de conhecimento e afinidade para elaborar o 
conteúdo teórico e em vídeo a ser trabalhado na capacitação dos mentores. O pilar "acadêmico" estruturou-se ao redor dos dois seguintes cenários: a apresentação do panorama geral dos seis anos de faculdade e as diferentes dinâmicas de estudo aplicáveis à realidade universitária. Assim, os tópicos abordados foram: panorama geral do curso de Medicina; conceito de revisão ativa; curva de esquecimento de Ebbinghaus; revisão ativa; e as diversas técnicas de estudo, tais como resumos, desgravação de aula, mapas mentais e flashcards. $\mathrm{O}$ pilar "desenvolvimento pessoal" englobou diversos assuntos relacionados à produtividade (Lean, 5S, P.A.R.A, GTD); manejo de tempo e prioridade (Matriz Eisenhower, técnica pomodoro, time blocking) e planejamento (diário, semanal, mensal). O pilar "extensão"encarregou-se de apresentar as diferentes oportunidades extracurriculares na IES, tais como ligas acadêmicas, órgãos (associações estudantis), times esportivos, bateria universitária, projetos de extensão, além de hobbies e lazer. E, por fim, o pilar "pesquisa" objetivou apresentar, em aspectos gerais, a realidade de pesquisa da universidade, a fim de incentivar a produção e a autonomia dos ingressantes quanto a essa temática. Foram abordados os seguintes tópicos: revista indexada, Plataforma Brasil, Currículo Lattes, curriculum vitae, bem como os tipos de produção científica.

- Segunda fase: pesquisa de interesse por mentores e pupilos em potencial, bem como sua seleção realizada por meio do preenchimento de formulários on-line. Os critérios de seleção para os pupilos foram: participação ativa nas atividades organizadas pela IFMSA Brazil FMT e estar cursando o primeiro ou segundo períodos do curso de Medicina da Unitau durante o ano de 2020. Para a seleção dos mentores, adotaram-se os seguintes critérios de seleção: ser membro do comitê local da IFMSA Brazil FMT, ter concluído o primeiro ano do curso de Medicina e apresentar, por meio do formulário on-line, uma carta de motivação, bem como um breve relato das experiências universitárias. Ambos os formulários foram analisados pela coordenação do projeto para a seleção dos candidatos.

- Terceira fase: disponibilização dos materiais elaborados pela coordenação do projeto sobre cada um dos pilares para capacitação dos mentores selecionados e de um modelo de planejamento completo e semanal, a fim de otimizar e facilitar a abordagem dos pilares nas reuniões semanais dos mentores com os seus pupilos. O material foi disponibilizado por meio do Google Drive, dentro de um tempo hábil para estudo antes do início das mentorias.

- Quarta fase: composta pelos quatro seguintes momentos, nesta ordem: 1. pareamento entre pupilos e mentores: no dia 5 de outubro de 2020, realizou-se uma live no Instagram da IFMSA Brazil FMT, na qual houve um sorteio, possibilitando a correspondência entre veteranos e calouros, que passaram a ser, respectivamente, mentores e pupilos; 2. desenvolvimento das mentorias propriamente ditas: elas começaram oficialmente por meio de reuniões remotas entre mentores e pupilos, com a periodicidade mínima de um encontro semanal, e a cada dupla era dotada de completa autonomia para a determinação dos demais aspectos; 3. análise dos feedbacks ao término da primeira edição do projeto: no dia 12 de dezembro de 2020, realizaram-se a coleta e a análise de feedback, envolvendo mentores e pupilos, por meio do Google Forms, a fim de avaliar, sob diferentes óticas, os resultados da primeira edição do projeto e promover mudanças e melhorias necessárias e cabíveis para a edição seguinte.

\section{DISCUSSÃO}

O sistema de mentoria, adotado em diversas IES ${ }^{5-9}$, tem se mostrado uma estratégia bastante promissora, empregada no preparo e na recepção do aluno, tanto para a vida acadêmica quanto para a vida profissional. Majoritariamente, esses sistemas possuem docentes como protagonistas, coordenadores e mentores, uma modalidade bastante benéfica para os pupilos, que podem absorver experiências e vivências do preceptor, além de já iniciarem um contato com a realidade da profissão e também sua rede de contatos dentro da área ${ }^{5-8}$. No mais, é possível implementar outro sistema adjunto: a mentoria vertical por pares ${ }^{9}$, exposta neste relato de experiência. Essa modalidade, administrada, coordenada e direcionada por e para alunos, traz consigo uma série de benefícios, entre os quais se destacam a análise e a abordagem mais minuciosas da demanda, tendo em vista que os veteranos experienciaram essa condição dos alunos recém-chegados. Durante o desenvolvimento da mentoria vertical por pares estudantis, exposto neste relato de experiência, foram realizados no total nove encontros entre os pares, durante os dois meses de mentoria de fato. Ao final desses encontros, observou-se, por meio da análise do feedback coletado ao final da mentoria, que o 
vínculo gerado entre calouro e veterano favoreceu a integração do pupilo com a comunidade universitária, fomentando seu engajamento com as atividades e oportunidades da IES. Isso pode ser ilustrado com a experiência observada no projeto aqui relatado, uma vez que, das 14 duplas de mentor-pupilo formadas ao início do projeto, a maioria relatou, por meio do feedback para os coordenadores, o desenvolvimento de uma relação amistosa e, em alguns casos, o início de uma amizade entre o mentor e o pupilo. Além da aproximação entre os alunos recém-ingressantes e seus colegas mais experientes, verificaram-se também, entre os alunos que participaram da primeira edição do projeto como pupilos, maior proatividade e maior engajamento com a comunidade universitária, pois a maioria, hoje, compõe a coordenação de diversos projetos liderados por alunos, como ligas acadêmicas, organizações estudantis, projetos de voluntariado e até mesmo a gestão desse projeto de mentoria, o que nos leva a inferir que isso se deve ao fruto direto do suporte técnico-prático fornecido pelos mentores ao longo do processo de mentoria. Dessa forma, podemos concluir, a partir da experiência obtida no projeto de mentoria desenvolvida por pares estudantis, que a expansão do projeto no próprio curso de Medicina, como também nos diferentes cursos de graduação da IES, é benéfica e possível de ser realizada, de maneira a ofertar a todos os alunos ingressantes interessados uma vaga, na posição de pupilo, a fim de estimular o engajamento social e estudantil e o desenvolvimento de uma cultura de acolhimento dentro do ambiente universitário.

\section{CONCLUSÃO}

Ao longo da primeira edição do projeto de mentoria por pares estudantis, discutida neste relato, o desenvolvimento de sessões semanais (nove no total) aproximou os pupilos (calouros) de seus mentores (veteranos), aumentando o engajamento de ambas as partes nas atividades fornecidas pela universidade, além de fornecer aos ingressantes uma visão mais clara, completa e imparcial de todos os trâmites que permeiam a vida acadêmica, como observado na análise do feedback ao final da mentoria. No que tange ao mentor, também foi assistido pelas capacitações referentes aos diferentes âmbitos da vida universitária. Mesmo com o tempo de execução do projeto reduzido, as expectativas iniciais foram atingidas, tendo em vista que houve a capacitação de pupilos e mentores com ferramentas para o seu amplo desenvolvimento no âmbito universitário, como observado pelo engajamento dos pupilos em projetos liderados por alunos. Assim, a partir dessa primeira edição do projeto, espera-se que o sentimento de pertencimento seja fortalecido, levando a uma maior e melhor integração dos calouros na vida universitária, fortalecendo uma cultura de acolhimento e proatividade entre os estudantes de Medicina, de forma horizontal e holística. No entanto, é importante mencionarmos as dificuldades encontradas. As principais limitações do projeto foram: número reduzido de participantes, composto por 14 duplas (28 participantes no total, sendo 14 mentores e 14 pupilos), as vagas para a categoria mentor foram ofertadas exclusivamente para coordenadores locais da IFMSA Brazil FMT, o tempo reduzido de mentoria efetiva (dois meses), bem como o fato de todo o processo ter sido desenvolvido exclusivamente por estudantes de Medicina (na categoria coordenação, mentor e pupilo). Esses aspectos estão sendo analisados e estudados para que possa ocorrer um aprimoramento nas edições seguintes do projeto, sempre objetivando a assistência mais efetiva e completa para os ingressantes, a fim de que possam desfrutar da vida acadêmica da forma mais plena e realizada possível. Compartilhando este relato, a equipe organizadora busca incentivar a criação de programas e projetos em outras IES voltados para o acolhimento do calouro por "veteranos" de uma forma mais holística.

\section{CONTRIBUIÇÃO DOS AUTORES}

Maria Stella Amorim da Costa Zöllner orientou a elaboração do artigo e participou da escrita, revisão e edição final do texto para submissão. Ayrton Kenji Kaji (autor principal) participou do rascunho e da escrita do texto. Beatriz Camargo Gazzi participou da escrita, revisão e edição do texto (corpo do relato: relato de experiência, discussão e conclusão). Bruna Schimitd participou da escrita, revisão e edição do texto, e foi responsável pela padronização para as normas do edital e pela revisão geral para envio à orientadora. Mariana de Jesus Silva formatou a folha de rosto, participou da escrita, revisão e edição do texto (corpo do relato: relato de experiência, discussão e conclusão), e desenvolveu o resumo, as palavraschave, o abstract e as keywords.

\section{CONFLITO DE INTERESSES}

Declaramos não haver conflito de interesses.

\section{FINANCIAMENTO}

Declaramos não haver financiamento.

\section{REFERÊNCIAS}

1. Dicionário Online de Português. Mentoria. Porto: 7Graus; 2021 [acesso em 7 fev 2021]. Disponível em: https://www.dicio.com.br/ mentoria/\#: :text=substantivo\%20feminino\%200f\%C3\%ADcio\%2C\%20 trabalho\%20ou,algu \%C3\%A9m\%20mais $\% 20$ jovem $\% 20$ e $\% 20$ inexperiente.

2. Teixeira MAP, Dias ACG, Wottrich SH, Oliveira AM. Adaptação à universidade em jovens calouros. Psicol Esc Educ. 2008;12(1):185-202 [acesso em 9 fev 2021]. Disponível em: https://www.scielo.br/scielo.php?script=sci arttext\&pid=S1413-85572008000100013\&lng=en\&nrm=iso. 
3. Diniz AM, Almeida LS. Adaptação à universidade em estudantes do primeiro ano: estudo diacrónico da interacção entre o relacionamento com pares, o bem-estar pessoal e o equilíbrio emocional. Anál Psicol. 2006;24(1):29-38 [acesso em 15 fev 2021]. Disponível em: http://www.scielo.mec.pt/scielo. php?script=sci_arttext\&pid=S0870-82312006000100004\&lng=pt\&nrm=iso.

4. Suehiro ACB. Estudante universitário: características e experiências de formação. Psico USF. 2004;9(1):105-6 [acesso em 17 fev 2021]. Disponível em: https://www.scielo.br/scielo.php?script=sci_ arttext\&pid=S1413-82712004000100013.

5. Pololi LH, Knight SM, Kay D, Frankel RM. Helping medical school faculty realize their dreams: an innovative, collaborative mentoring program. Acad Med. 2002 May; 77(5):377-84 [acesso em 22 fev 2021]. Disponível em: https://journals.Iww.com/academicmedicine/Fulltext/2002/05000/ Helping_Medical_School_Faculty_Realize_Their.5.aspx.
6. Frei E, Stamm M, Buddeberg-Fischer B. Mentoring programs for medical students - a review of the PubMed literature 2000-2008. BMC Med Educ. 2010;(10):32. doi: 10.1186/1472-6920-10-32.

7. Hauer KE, Teherani A, Dechet A, Aagaard EM. Medical students' perceptions of mentoring: a focus-group analysis. Med Teach. 2009;27(8):732-4. doi: 10.1080/01421590500271316.

8. Nimmons D, Giny S, Rosenthal J. Medical student mentoring programs: current insights. Adv Med Educ Pract. 2019;10:113-23. doi: 10.2147/AMEP. S154974.

9. Andre C, Deerin J, Leykum L. Students helping students: vertical peer mentoring to enhance the medical school experience. BMC Res Notes. 2017;10:176. doi: 10.1186/s13104-017-2498-8. 